\title{
A organização do conhecimento: Estudo bibliométrico na base de dados ISI Web of Knowledge
}

\author{
Cláudia Daniele de Souza \\ Universidade Federal de São Carlos - UFSCar, Brasil
}

ARTIGO / ARTICLE

\begin{abstract}
Resumo
A Organização do Conhecimento é uma área de múltiplas aplicações e muito tradicional na pesquisa/ensino em Ciência da Informação. Grande parte da literatura trata do processo, das atividades e dos instrumentos especialmente desenvolvidos no tratamento de documentos para armazenamento, disseminação, recuperação e uso em sistemas e serviços de informação. $O$ presente artigo apresenta uma análise bibliométrica sobre a atividade científica no campo da Organização do Conhecimento, utilizando-se publicações da base de dados ISI Web of Science - WoS. A importância do estudo bibliométrico é sustentada pela necessidade de se conhecer e avaliar a produtividade e mensurar pesquisas e autores, permitindo a detecção de modelos e padrões sobre a Organização do Conhecimento. Os procedimentos metodológicos são do tipo exploratório-descritivo e algumas etapas foram estabelecidas para melhor desdobramento: revisão bibliográfica para fundamentar a pesquisa, identificação da base de dados, elaboração da expressão de busca, coleta de dados, organização e tratamento bibliométrico com o software Vantage Point e por fim, representações gráficas com o auxílio do Microsoft Excel. Dentre os resultados da pesquisa, destaca-se que nos últimos 20 anos há um crescimento constante das publicações científicas sobre Organização do Conhecimento e que o país que lidera o ranking dos que mais publicam sobre o tema é o Canadá, ficando o Brasil em oitavo lugar.
\end{abstract}

\section{Palavras-chave}

Ciência da Informação ; Organização do Conhecimento ; Análise Bibliométrica ; Indicadores bibliométrico

\section{The organization of knowledge: bibliometric study in database ISI Web of Knowledge}

\begin{abstract}
The Organization of Knowledge is an area of multiple applications and very traditional in research / teaching in Information Science. Most of the literature deals with the process, activities and tools specially developed for the treatment of documents for storage, dissemination, retrieval and use of information systems and services. This paper presents a bibliometric analysis of scientific activity in the field of Knowledge Organization, using publications database ISI Web of Science - WoS. The importance of bibliometric study is underpinned by the need to understand and evaluate and measure research productivity and authors, allowing the detection of designs and patterns on the Organization of Knowledge. The methodological procedures are exploratory-descriptive and some steps have been established to better deployment: a literature review to support the research, identification database, preparation of expression search, data collection, organization and bibliometric treatment with Vantage Point software and finally graphical representations with the aid of Microsoft Excel. Among the search results, it is noteworthy that in 20 years there is a steady growth of scientific publications on Knowledge Organization and the country that leads the ranking of the fastest publish on the subject is Canada, Brazil being the eighth.
\end{abstract}

Keywords

Information Science ; Knowledge Organization ; Bibliometric Analysis ; Bibliometric indicators 


\section{Introdução}

A Organização do Conhecimento é uma área central de ensino e pesquisa em Ciência da Informação e Biblioteconomia. A importância de um estudo bibliométrico sobre a Organização do Conhecimento é sustentada pela necessidade de se conhecer e avaliar a produtividade e mensurar a pesquisa e seus atores (autores/pesquisadores), permitindo a deteç̧ão de modelos e padrões da atividade científica. Eles ajudaram a entender como o conhecimento científico é difundido e incorporado entre os atores e seus pares, bem como entre o público em geral.

Pode-se afirmar que os estudos bibliométricos têm sido cada vez mais requisitados e utilizados para a quantificação da produção e também para outras finalidades, como identificar grupos e áreas de excelência acadêmica. Este artigo pretende conceituar o que é a Organização do Conhecimento e o que está sendo produzido e publicado nessa temática, tendo como instrumento alguns indicadores bibliométricos. O objetivo é mapear a atividade científica sobre a temática Organização do Conhecimento, publicadas em todo o período de abrangência da base de dados ISI Web of Science - WoS.

\section{Organização do conhecimento}

É reconhecida a necessidade de se organizar o conhecimento registrado e este processo envolve representantes de diversas áreas do saber. Bräscher e Café (2008) analisaram o emprego do termo Organização do Conhecimento em diferentes contextos e observaram a falta de clareza quanto à delimitação desse conceito. Da mesma forma, Brandt (2009, p. 19) em sua dissertação de Mestrado afirma que não há um consenso sobre o conceito de Organização do Conhecimento. Portanto, com o intuito de fundamentar este artigo faremos uso de algumas teorias e metodologias de Organização do Conhecimento referentes à Biblioteconomia, Documentação, Ciência da Informação e Comunicação.

O conceito de Organização do Conhecimento é um conceito antigo com que o homem tem convivido e provém basicamente da filosofia e da classificação das ciências (MONTEIRO E GIRALDES, 2008).

Fujita (2001, p.29) explica que, baseada em práticas e atividades significativas de armazenagem de recuperação de documentos no decorrer da sistematização do conhecimento humano, a Organização do Conhecimento tem suas origens na criação, por bibliotecários, de sistemas de classificação como instrumentos de organização temática de documentos para armazenagem. Nesse sentido, Smiraglia (2002, p. 331) relata que a Organização do Conhecimento, no âmbito da Biblioteconomia e Ciência da Informação é o ramo do conhecimento da construção de ferramentas para o armazenamento e recuperação de entidades documentárias.

De acordo com Hjørland (2003, p. 87) o conceito de Organização do Conhecimento para a comunidade da Biblioteconomia e Ciência da Informação significa especialmente a organização da informação em registros bibliográficos, incluindo índices de citação, texto completo e internet. Para Anderson (1996, p. 337), a Organização do Conhecimento é definida como a descrição de documentos, seu conteúdo, características e propósitos, e a organização destas descrições, para fazer destes documentos e de suas partes acessíveis às pessoas, buscando-os ou as mensagens que eles contêm. Cerca todo tipo e método de indexação, resumo, catalogação, classificação, gerenciamento de registros, bibliografia e a criação de bases de dados textuais para a recuperação da informação.

Na visão de Rowley (1992, p. vxii) a Organização do Conhecimento é o caminho para estabelecer sistemas para organizar documentos e informação, permitindo que eles possam ser recuperados pelos usuários sempre que requisitados. Já para Dahlberg (2006) a Organização do Conhecimento é a ciência que ordena a estruturação e sistematização dos conceitos, de acordo com suas características, que podem ser definidas como elementos de herança do objeto, e a aplicação dos conceitos e classes dos conceitos ordenados pela indicação de valores, dos referentes conteúdos dos objetos ou assuntos. A partir dessa Organização do Conhecimento criam-se ferramentas que apresentam a interpretação organizada e estruturada do objeto, chamados de sistemas de Organização do Conhecimento.

De acordo com Barité (2001, p. 38) a Organização do Conhecimento oferece, ou busca oferecer, tudo o que é relativo ao tratamento da informação quanto a sua tematicidade e seu uso social habitual. Para Bufrem (2004, p. 2) a categoria temática Organização do Conhecimento (Knowledge Organization) relaciona-se originalmente às tarefas 
de classificar, indexar e representar o conhecimento por meio de registros informatizados para atender as necessidades mais urgentes de informação.

Para Esteban Navarro (1996, p. 97-98), a Organização do Conhecimento é a disciplina específica que se dedica dentro da Ciência da Informação Documental ao estudo dos fundamentos teóricos do tratamento e da recuperação da informação e a construção, manutenção, uso e avaliação dos instrumentos lógico-linguísticos mais adequados para controlar os processos de representação, classificação, ordenação e armazenamento do conteúdo informativo dos documentos com o fim de permitir sua recuperação e comunicação. Ocupa-se, portanto, dos princípios e ferramentas postas em ação para a gestão do conhecimento humano desde uma tripla perspectiva: sua representação, sua organização e sua comunicação documental.

No que tange ao ensino de Biblioteconomia, Pando e Guimarães (2006) dizem que a questão da Organização do Conhecimento está inserida especificamente na área de Tratamento Temático da Informação, que tem como objetivo a identificação, o processamento e a disponibilização do conteúdo informacional dos documentos e suas interfaces com as teorias e os sistemas de armazenamento e recuperação da informação.

Finalmente, para Broughton (2004, p. 142) a Organização do Conhecimento enquanto disciplina da Ciência da Informação aborda assuntos como os sistemas de classificação, a análise facetada, criada por Ranganathan; a recuperação da informação, em que a Organização do Conhecimento é a base para o bom desempenho deste campo; a visão cognitiva para análise de domínio e a abordagem bibliométrica.

\section{Bibliometria e indicadores}

Segundo Pritchard (1969) a bibliometria é um campo da Ciência da Informação que aplica métodos estatísticos para analisar e quantificar os processos de comunicação escrita de uma determinada disciplina. Iniciada no século XIX e sistematizada a partir do século XX, o intuito é estudar e avaliar as atividades de produção científica. 0 desenvolvimento deu-se tendo como principal marco os estudos a partir de leis empíricas sobre o comportamento da literatura. (TAGUESUTCLIFFE, 1992, apud ARAUJO, 2006, p. 12).

De acordo com Spinak (1998) a bibliometria estuda a organização dos setores científicos e tecnológicos a partir de fontes bibliográficas e patentes para identificar autores, suas relações e tendências. Trata das várias formas de medir a literatura dos documentos e outros meios de comunicação e é importante, pois permite identificar tendências e crescimento, usuários e autores, verificar a cobertura das revistas, medir a disseminação da informação e também formular políticas.

A análise da atividade científica de um país, de uma região ou instituição específica envolve um conjunto expressivo de indicadores bibliométricos. Eles podem ser divididos em indicadores de produção, indicadores de citação e indicadores de ligação (NARIN, 1994).

Os indicadores de produção científica são construídos pela contagem do número de publicações por tipo de documento (livros, artigos, publicações científicas, relatórios, etc.), por instituição, área conhecimento, país, etc. O indicador básico é o número de publicações, que procura refletir características da produção ou do esforço empreendido, mas não mede a qualidade das publicações (SANTOS et al., 2007).

Segundo Faria (2001, p. 9) os indicadores são uma forma de sintetizar e agregar valor à informação. Através da Figura 01 é possível observar como ocorre a análise bibliométrica agregando valor a informação. 


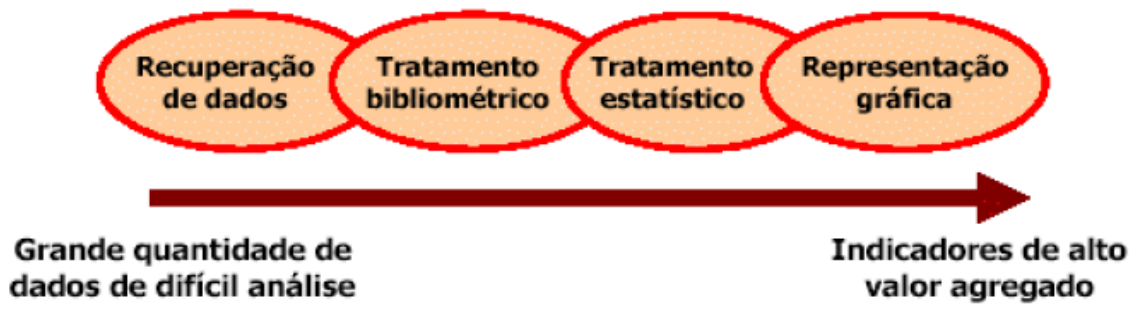

É possível trabalhar com uma grande quantidade de dados, seguindo com tratamentos bibliométricos e estatísticos e por fim prepará-los para os fins a que se dedicam os indicadores. É visível a importância da bibliometria, levando em consideração que a produção do conhecimento científico dá-se sempre sem pausa, em baixa ou larga escala.

Neste estudo, pretendemos utilizar os indicadores bibliométricos de produção científica para quantificar 'coisas' intangíveis: evolução da atividade científica ao longo do tempo; principais palavras-chave indexadas nas publicações; países que mais publicam sobre a Organização do Conhecimento; idiomas mais freqüentes; instituições que mais publicam sobre o assunto; títulos de periódicos que mais possuem publicações sobre a Organização do Conhecimento e também autores que mais publicam nessa temática.

\section{Procedimentos metodológicos}

Os procedimentos metodológicos desta pesquisa são do tipo exploratório-descritivo, visando proporcionar maior familiaridade com o problema, buscando torná-lo explícito, estabelecendo relações entre as variáveis e envolvendo o uso de técnicas padronizadas de coleta de dados na forma de levantamento.

Para fins de melhor desdobramento, foram estabelecidas algumas etapas, a saber:

- Revisão bibliográfica - Revisão de literatura sobre Organização do Conhecimento e também Análise bibliométrica, com o objetivo de fundamentar teoricamente a pesquisa;

- Identificação da Base de Dados - Análise das possibilidades de cobertura que a Web of Science - WoS oferece em termos de área e período; conforme Santos et al (2007, p. 03):

\footnotetext{
"a produção de indicadores da ciência, por métodos bibliométricos, requer um conjunto de dados padronizados, sistematizados e consistentes, em princípio encontráveis nas bases de dados bibliográficas."
}

Optou-se por recuperar esses dados na base WoS que foi produzida pelo ISI - Institute for Scientific Information e atualmente é do grupo empresarial Thomson Reuters. Ela está disponível desde 1997, têm abrangência internacional e contém informações bibliográficas e citações de aproximadamente 40 milhões de artigos científicos, publicados a partir de 1945 em mais de 230 disciplinas. Além disso, a WoS oferece registros bibliográficos padronizados, dando a possibilidade de trabalhar com o software Vantage Point, que auxilia na contagem, padronização e organização dos dados. 
- Elaboração da expressão de busca - Observou-se na literatura a expressão mais utilizada para representar o conceito; assim, com o intuito de delimitar a pesquisa, optouse por pesquisar nos campos título, resumo e palavras-chave (Topic - TS) a seguinte expressão de busca em inglês:

$$
\text { Topic=("knowledge organization") }
$$

As aspas serviram para recuperar as duas palavras juntas e evitar a recuperação de cada uma isoladamente. Assim, obteu-se 396 registros, entretanto, pelo fato do ano de 2011 ainda não estar completo, este foi excluído e quantidade final foi de 389 registros.

- Coleta de dados - Busca e recuperação dos registros bibliográficos da WoS em formato .txt que é reconhecido pelo software de tratamento bibliométrico utilizado, o Vantage Point;

Mais comumente, os estudos bibliométricos tendem a analisar apenas os artigos científicos contidos nos periódicos indexados, assumindo que estes têm maior qualidade e são mais representativos da atividade científica do que os artigos de revisão, cartas e outros. Entretanto, da mesma forma que Lima e Velho (2008), decidiu-se aqui incluir todos os tipos de publicação, uma vez que, o objetivo é analisar a atividade de pesquisa (e não somente a produção científica) e essa está refletida não apenas na publicação dos resultados em artigos, mas também nas demais formas de comunicação científica.

- Organização e tratamento bibliométrico - Importação dos registros bibliográficos para o Vantage Point e padronização de termos relativos à nomes de instituições e títulos de periódicos. Criação de listas para visualização dos dados.

- $\quad$ Representações gráficas - Exportações das listas para o software Microsoft Excel e elaboração de figuras para apresentação e análise dos resultados.

\section{Resultados}

Como resultados desta pesquisa, a partir da WoS foram elaborados oito indicadores da atividade científica sobre a Organização do Conhecimento, que serão apresentados e discutidos a seguir. São eles:

- Evolução da atividade científica ao longo do tempo;

- Principais palavras-chave indexadas nas publicações;

- Países que mais publicam sobre a Organização do Conhecimento;

- Idiomas mais freqüentes;

- As dez instituições que mais publicam sobre o assunto;

- Títulos de periódicos que mais possuem publicações sobre a Organização do Conhecimento;

- $\quad$ Os dez autores que mais publicam nessa temática. 
Inicialmente, com o objetivo de mensurar o número de publicações científicas geradas ao longo do tempo, verificouse que na WoS surgem publicações sobre a Organização do Conhecimento a partir de 1979 (Figura 2).

Figura 2: Evolução da atividade científica sobre Organização do Conhecimento na WoS.

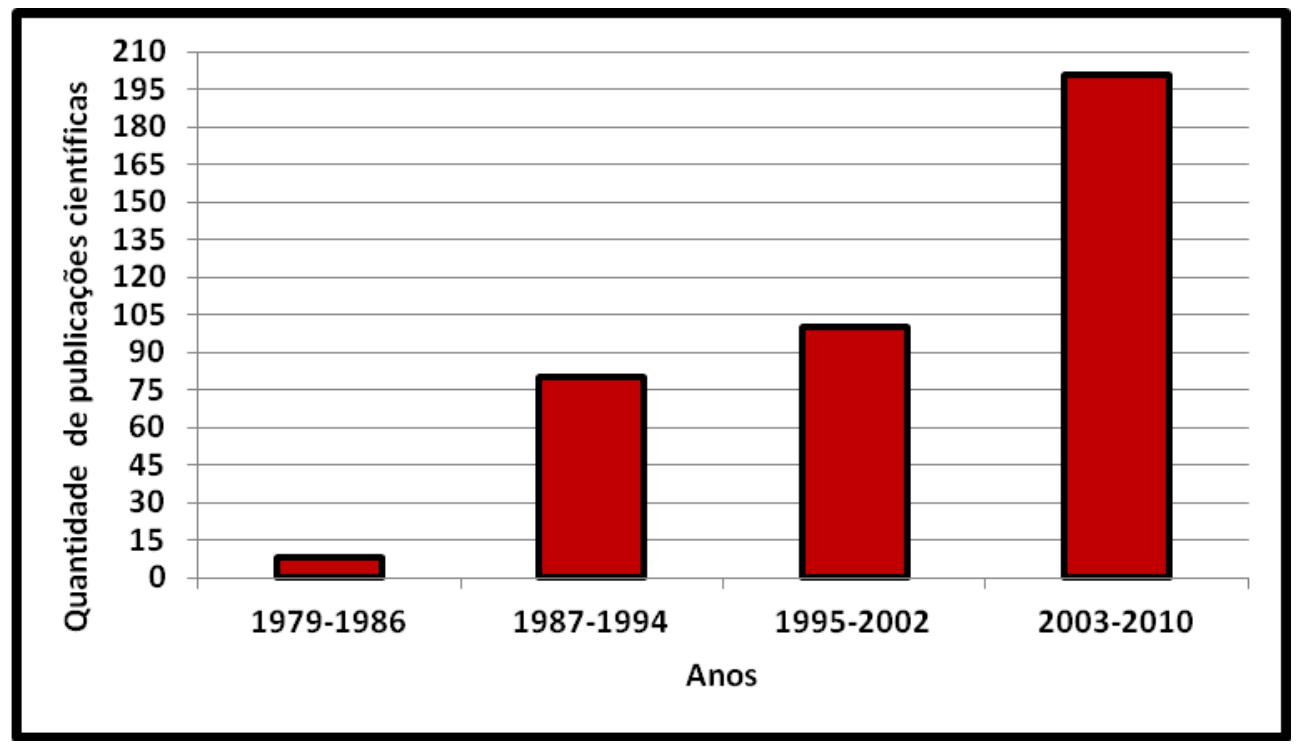

Entretanto, a quantidade de publicações começa a crescer e ser relevante somente no início da década de 1990. Tal fato pode estar atrelado à fundação da International Society for Knowledge Organization - ISKO - em 22 de julho de 1989. Uma sociedade científica da área de Organização e Representação do Conhecimento, responsável pelas principais ações em torno de sua consolidação científica. Com um escopo amplo e interdisciplinar, a ISKO conta com mais de 400 membros em todo o mundo, interessados em fazer avançar os trabalhos conceituais na Organização do Conhecimento em todos os tipos de formas e para todos os tipos de finalidades, tais como bancos de dados, bibliotecas, dicionários e internet (INTERNATIONAL..., 2011).

A explicação de Fujita (2008, p. 4) complementa e reforça a análise:

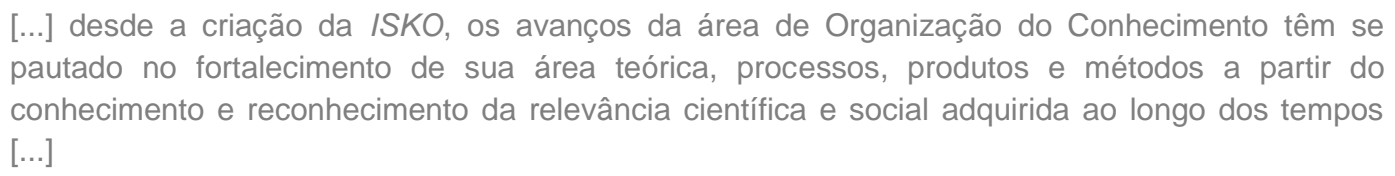

O segundo indicador elaborado nesta pesquisa diz respeito às palavras-chave (Figura 3) que se destacam nas publicações científicas sobre Organização do Conhecimento presentes na WoS. 
Figura 3: As palavras-chave mais presentes nas publicações científicas sobre Organização do Conhecimento.

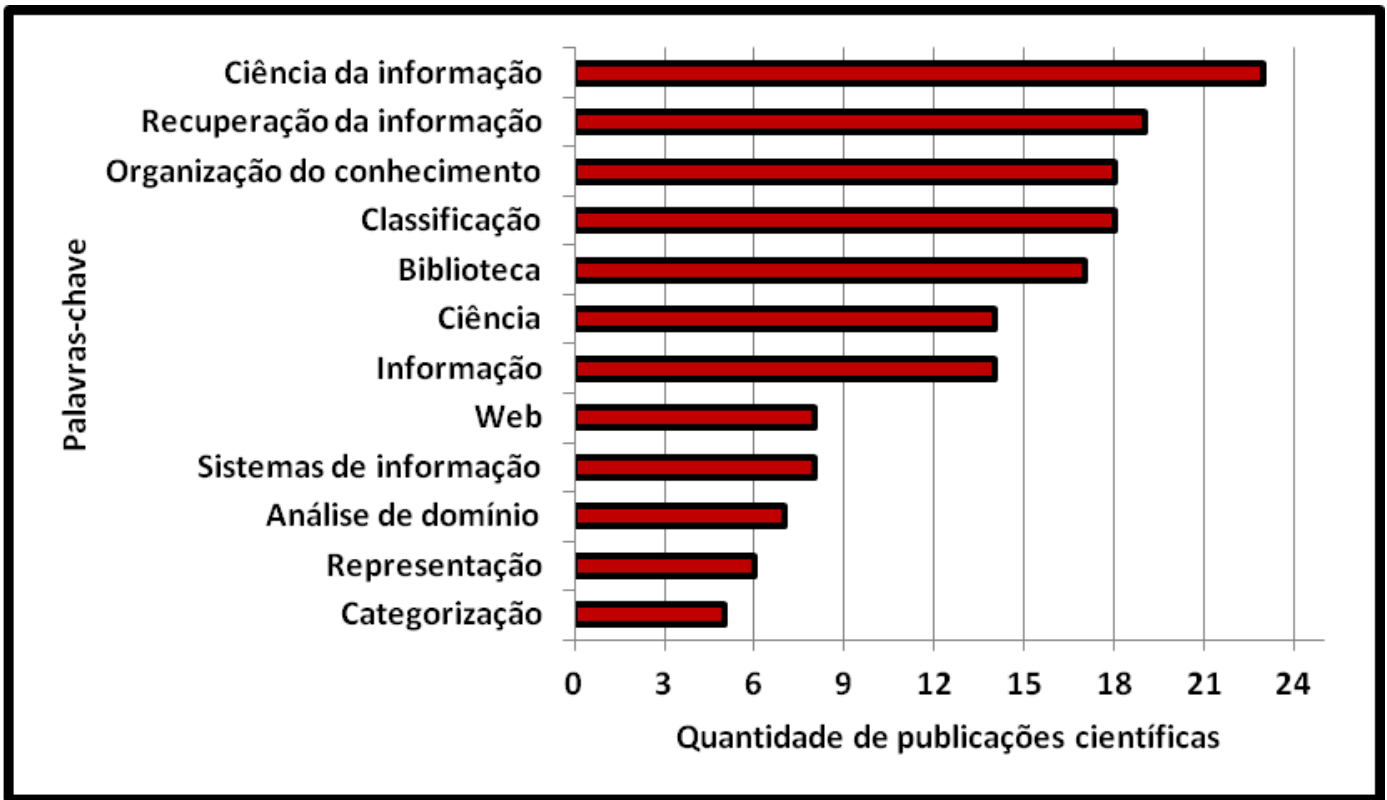

Percebe-se que Ciência da Informação e Recuperação da Informação são as duas palavras-chave mais frequentes, presentes em 23 e 19 publicações científicas, respectivamente. Ambas têm relação direta com a Organização do Conhecimento como Monteiro e Giraldes (2008, p. 13) explicam:

[...] o que se observa é que a Organização do Conhecimento tem provocado atenção de vários pesquisadores [...] a preocupação comum é viabilizar o acesso ao conhecimento e à informação.

Porém para fazer uso desse conhecimento e dessa informação é necessário que ambos estejam disponibilizados de uma forma rápida e acessível. Dessa forma, justifica-se que Classificação, processo que sumaria e ordena 0 conhecimento existente (TRISTÃO; FACHIN; ALARCON, 2004), seja a quarta palavra chave mais presente (18 publicações).

No contexto mundial, o país que mais se destaca na atividade científica relacionada à Organização do Conhecimento, conforme a Figura 4, é o Canadá com 33 publicações. Em seguida está a Dinamarca (24), França (17), Inglaterra (14), Alemanha (13), Espanha (12) e Itália (9). O Brasil posiciona-se em oitavo lugar no ranking, com nove publicações sobre a Organização do Conhecimento indexados na WoS. Entretanto, com a instalação da ISKOBrasil em 2007, durante o VIII ENANCIB (Encontro Nacional da Associação Nacional de Pesquisa e Pós-Graduação em Ciência da Informação) em Salvador, acreditamos que a participação brasileira nas publicações deverá aumentar exponencialmente nos próximos anos. 
Figura 4: Principais países que publicam sobre a Organização do Conhecimento.

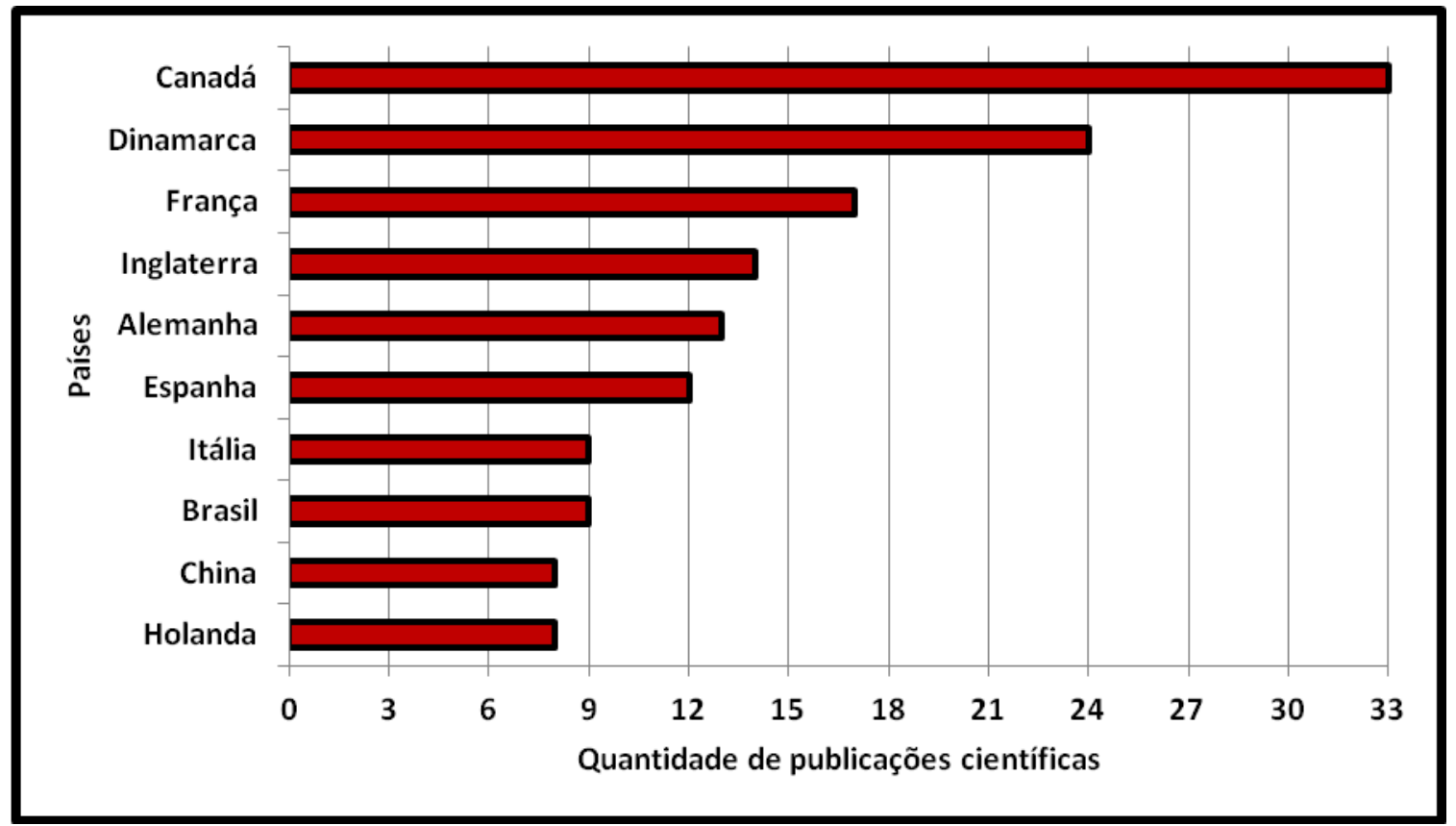

Seguindo os mesmos preceitos da ISKO Internacional, a ISKO-Brasil é uma sociedade interdisciplinar que reúne profissionais de diferentes áreas. Atualmente, seus mais de 100 membros por todo o país, representam os campos da Ciência da Informação, Filosofia, Lingüística, Ciência da Computação, Artes, História, bem como domínios específicos.

Na Figura 5 estão apresentados os cinco principais idiomas das publicações sobre Organização do Conhecimento indexadas na base WoS.

Figura 5: Os cinco principais idiomas.

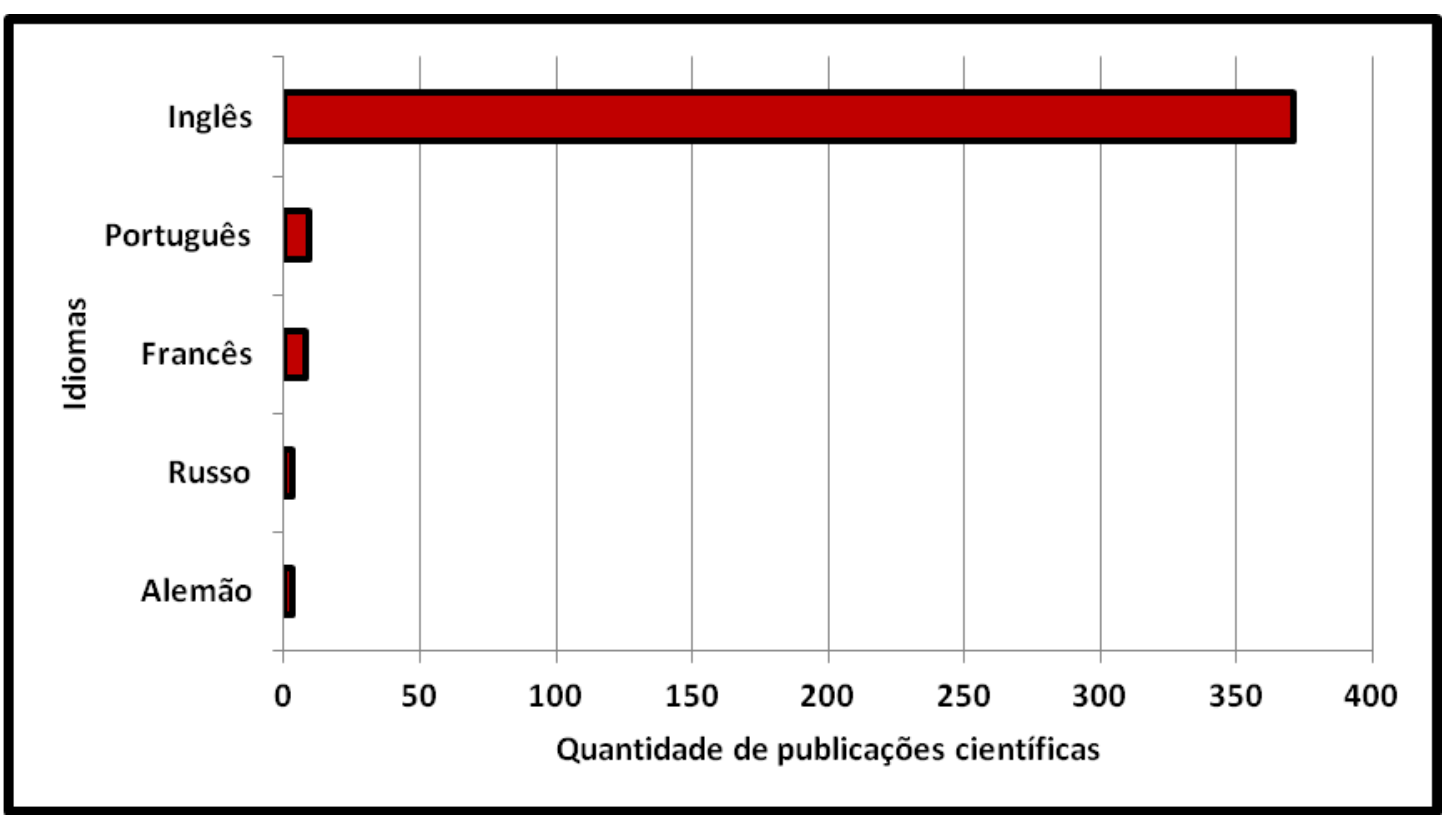


Provavelmente pelo fato de artigos publicados em outra língua que não o inglês terem menos chances de serem citados, independentemente da sua qualidade, $94 \%$ das publicações científicas sobre Organização do Conhecimento estão em inglês; de todo o universo, apenas nove publicações foram escritas em português, oito em francês, três em russo e três em alemão.

A Royal School of Library and Information Science - RSLIS é a instituição que mais possui artigos indexados na WoS, conforme a Figura 6. Localizada em Copenhagen, na Dinamarca, a RSLIS foi fundada em 1956 e oferece ensino superior de qualidade na área de Biblioteconomia e Ciência da Informação.

Figura 6: As dez instituições que mais publicam sobre o tema Organização do Conhecimento.

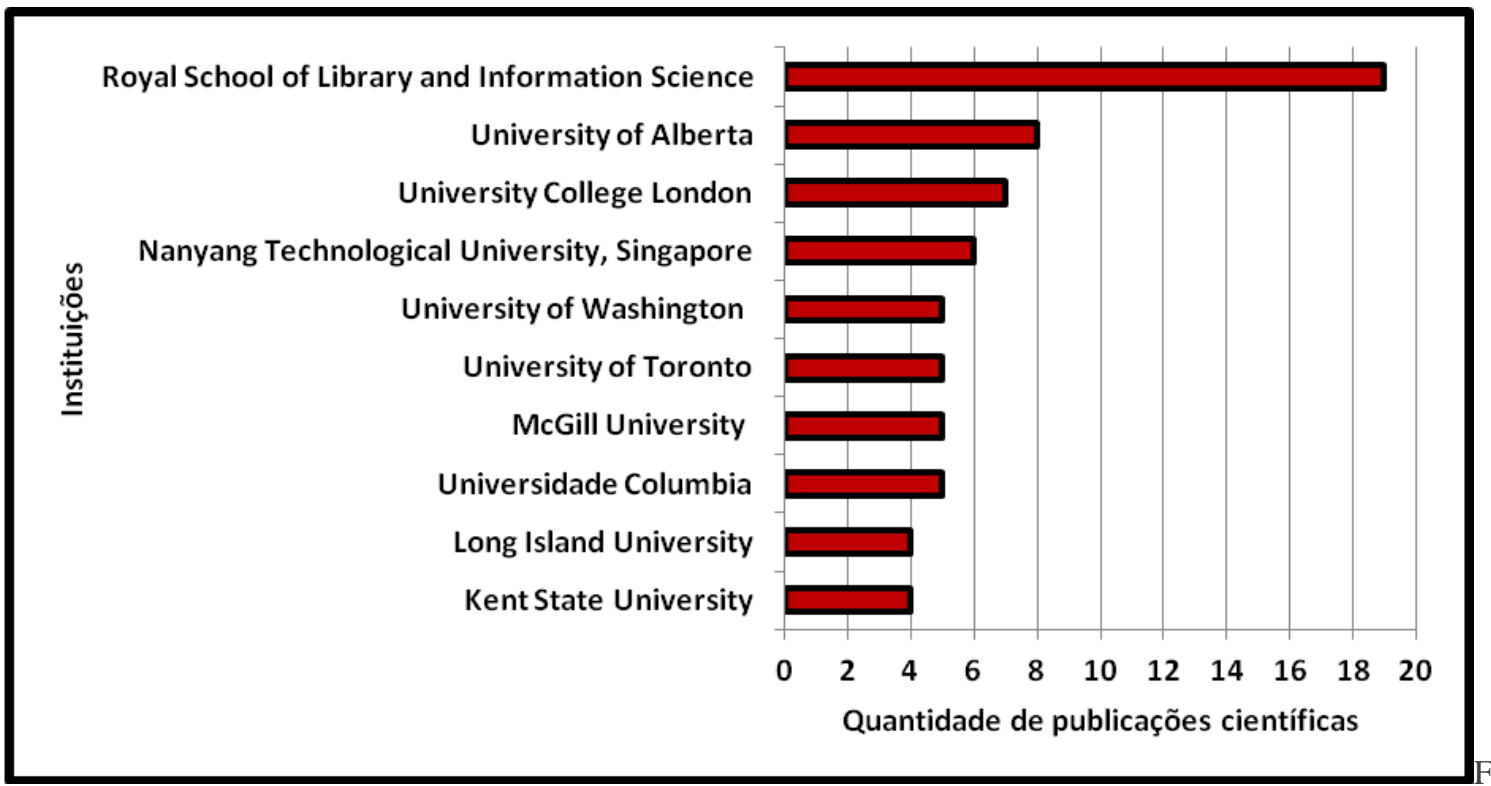

Em segundo lugar no ranking das instituições, está a Universidade de Alberta. Uma instituição de pesquisa fundada em 1908 e amplamente reconhecida como uma das melhores universidades do Canadá.

Knowledge Organization é o periódico oficial trimestral da ISKO e de acordo com a Figura 7 é o que possui $30 \%$ das publicações sobre a Organização do Conhecimento. Foi fundado em 1973 e tem como intuito:

- Traçar a história da Organização do Conhecimento;

- Esclarecer os fundamentos teóricos

- Descrever operações práticas associadas com a indexação e classificação, bem como aplicações de sistemas de classificação e thesauro, indexação manual e automática;

- Discutir questões de educação e formação na classificação, e

- Problemas de terminologia em geral e com relação a campos especiais

- (INTERNATIONAL..., 2011). 
Figura 7: Ranking dos dez periódicos que possuem mais publicações sobre a Organização do Conhecimento.

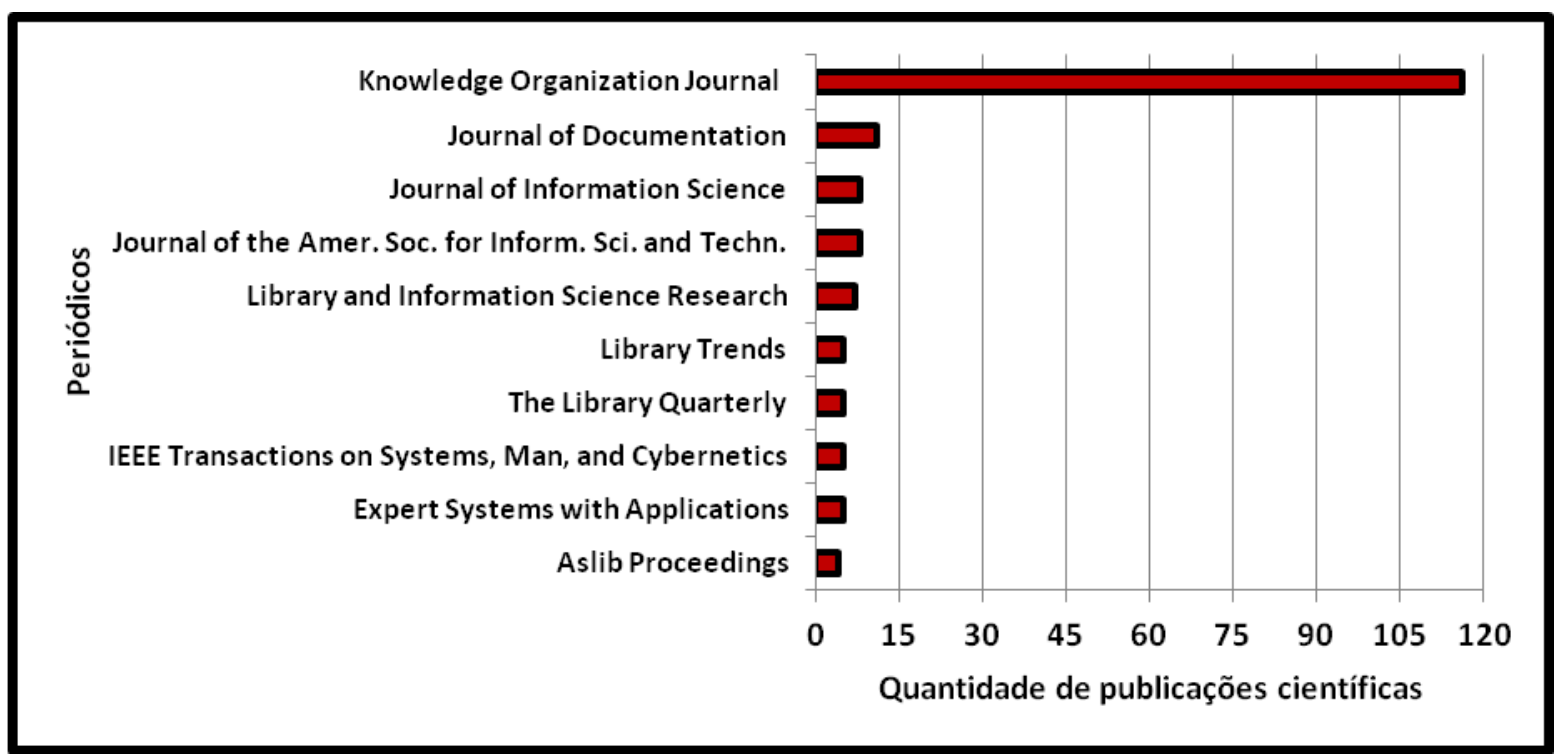

De acordo com a Figura 8, Ingetraut Dahlberg e Birger Hjørland são dois autores principais quando se trata de publicações sobre a Organização do Conhecimento no contexto da Ciência da Informação.

Figura 8: Os dez autores que mais publicam sobre a Organização do Conhecimento.

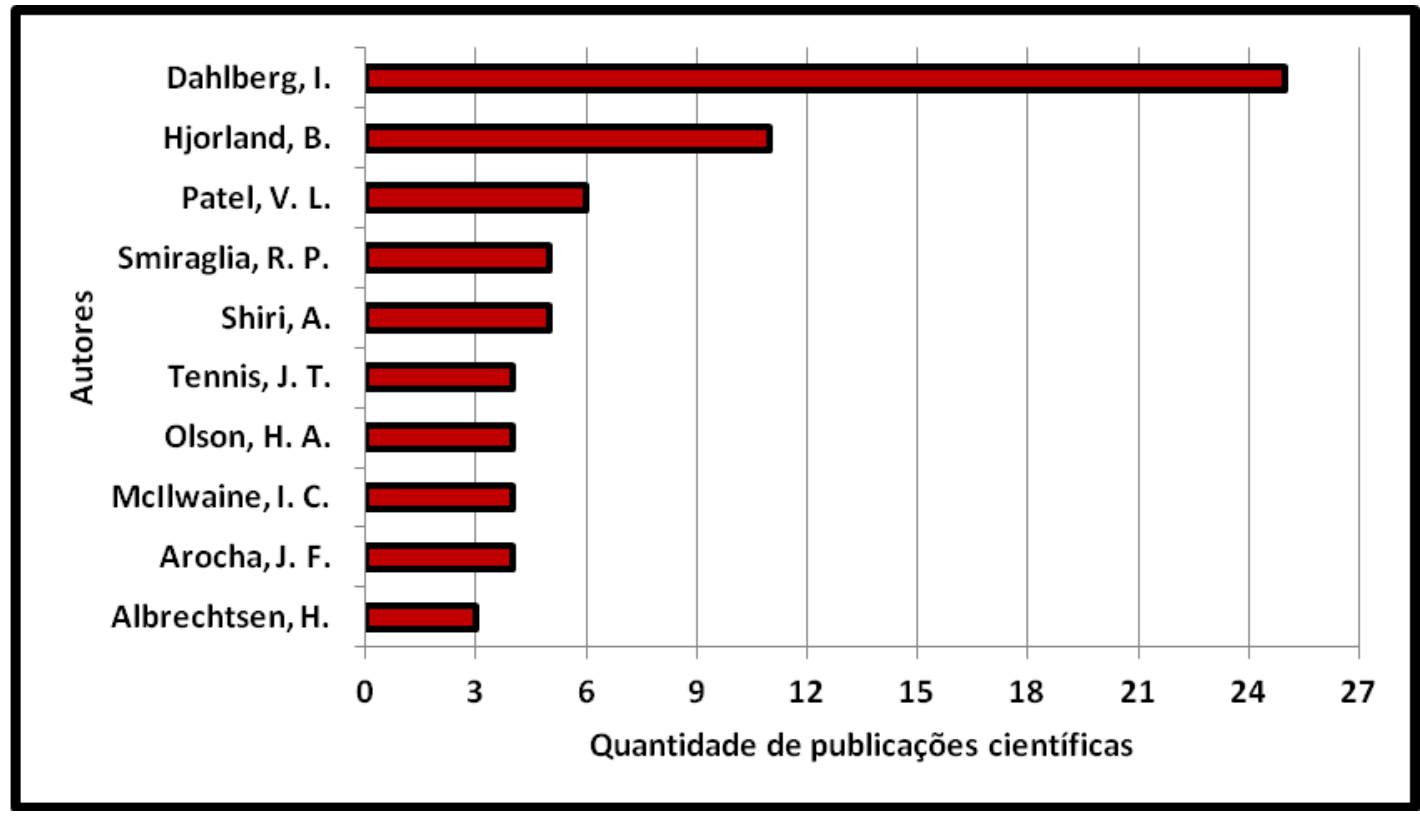

A primeira é bibliotecária e filósofa alemã, ficou amplamente conhecida na área por fundar a ISKO e definir a Teoria do Conceito (Dahlberg, 1978); já o segundo é doutor em Ciência da Informação e ministra aulas na RSLIS desde 2001 (Hjørland, 2008). 


\section{Considerações finais}

A bibliometria vem sendo utilizada nas diversas áreas do conhecimento como metodologia para a obtenção de indicadores de avaliação da atividade científica. De uma forma geral, o princípio é analisar a atividade científica ou técnica pelo estudo quantitativo das publicações e o seu principal objetivo é o desenvolvimento de indicadores cada vez mais confiáveis (SANTOS, 2003).

Os recursos disponíveis na base de dados WoS mostram-se bastante interessante para a realização de estudos deste tipo, além de propiciar a possibilidade de estudos posteriores com análise de outros indicadores. A contribuição desta pesquisa para a Ciência da Informação deve-se aos indicadores resultantes, principalmente na quantificação de 'coisas' intangíveis. Ressaltamos que a utilização da análise bibliométrica configura-se como uma metodologia importante para a Ciência da Informação, uma vez que é capaz de revelar padrões de pesquisa e identifica tendências.

Quanto às perspectivas, o passar dos últimos vinte anos demonstrou a evolução dos interesses e focos de investigação sobre a temática Organização do Conhecimento. Acreditamos que o Brasil tem grande potencial e, com a criação da ISKO-Brasil, deverá participar cada vez mais ativamente das pesquisas e publicações dessa temática.

\section{Bibliografía}

ANDERSON, J. D. Organization of knowledge. In: FEATHER, J.; STURGES, P. (Ed.). International encyclopedia of information and library science. London: Routledge, 1996. p. 336-353.

ARAÚJO, C. A. Bibliometria: evolução, história e questões atuais. Em Questão, Porto Alegre, v. 12, n. 1, p. 11-32, jan./jun. 2006.

BARITÉ, M. Organización del conocimiento: un nuevo marco teórico-conceptual en Bibliotecologia y Documentación, Organização do Conhecimento. In: Carrara, K. (Org.) Educação, universidade e pesquisa. Marília: Unesp Marília Publicações; São Paulo: FAESP, 2001. p. 35-60.

BRANDT, M. B. Etiquetagem e folksonomia: uma análise sob a óptica dos processos de organização e recuperação da informação na web. 144 f. Dissertação (Mestrado) - Departamento de Faculdade de Ciência da Informação, Universidade de Brasília, Brasília, 2009.

BRÄSCHER, M.; CAFÉ, L. Organização da Informação ou Organização do Conhecimento? In: ENCONTRO NACIONAL DE PESQUISA EM CIÊNCIA DA INFORMAÇÃO, 9, 2008, São Paulo, Anais. São Paulo: ANCIB, 2008.

BROUGHTON, V. et al. Knowledge Organization. In: Kajberg, L.; Lorring, L. European Curriculum Reflections on Library and Information Science Education. Copenhagen: Royal School of Library and Information Science, 2004. Cap. 7, p. 133-148.

BUFREM, L. S. Levantando significações para significantes: da gestão do conhecimento a organização do saber. Revista Eletrônica Biblioteconomia Ciência da Informação, Florianópolis, n. esp., 1ํㅗsem. 2004.

Dahlberg, I. Teoria do conceito. Ciência da Informação, v. 7, n. 2, p.101-107, 1978.

Dahlberg, I. Knowledge Organization. 2006. Disponível em:

<http://www.db.dk/bh/lifeboat ko/CONCEPTS/knowledge organization Dahlberg.htm> Acesso em:. 15 Jul 2011.

ESTEBAN NAVARRO, M. A. El marco disciplinar de los lenguajes documentales: la Organización del Conocimiento y las ciencias sociales. Scire, v. 2, n. 1, 1996, p. 93-107.

FARIA, L. I. L. Prospecção tecnológica em materiais: aumento da eficiência do tratamento bibliométrico: uma aplicação na análise de tratamento de superfícies resistentes ao desgaste. 176 f. Tese (Doutorado em Engenharia de Produção) - Universidade Federal de São Carlos, São Carlos, 2001.

FUJITA, M. S. L. Organização do Conhecimento: algumas considerações para o tratamento temático da informação, Organização do Conhecimento. In: Carrara, K. (Org.) Educação, universidade e pesquisa. Marília: Unesp Marília Publicações; São Paulo:

FAESP, 2001. p. 29-34. 
FUJITA, M. S. L. Organização e representação do conhecimento no Brasil: análise de aspectos conceituais e da produção científica do ENANCIB no período de 2005 a 2007. Tendências da Pesquisa Brasileira em Ciência da Informação, p.1-32, 2008.

HJøRLAND, B. Fundamentals of knowledge organization. Knowledge Organization, v. 30, n. 2, p. 87-111, 2003.

HJØRLAND, B. What is Knowledge Organization (KO)? Knowledge Organization: international journal devoted to concept theory, classification, indexing, and knowledge representation, Frankfurt, v. 35, n. 2/3, p. 86-101, 2008.

International Society for Knowledge Organization. ISKO's mission. Disponível em: <http://www.ISKO.org/about.html> Acesso em: 07 Jul. 2011.

LIMA, R. A.; VELHO, L. M. L. S. Indicadores Ibero-Americanos de atividade científica em bioprospecção. Revista Digital de Biblioteconomia e Ciência da Informação, v. 06, n. 01, p.1-14, 2008.

MONTEIRO, S. D.; GIRALDES, M. J. C. Aspectos lógico-filosóficos da Organização do Conhecimento na esfera da Ciência da Informação. Informação \& Sociedade: Estudos, João Pessoa, v. 18, n. 03, p.13-27, 2008.

NARIN, F.; OLIVASTRO, D.; STEVENS, K. S. Bibliometric theory, practive and problem. Evaluation Review, v. 18, n. $01,1994$.

PANDO, D. A.; GUIMARÃES, J. A. C. O Profissional da informação e as atividades de organização da informação / conhecimento. Interatividade, v.1, n. 2, 2006.

PRITCHARD, A. Statistical bibliography or bibliometrics? Journal of Documentation, v. 25, n. 4, p. 348-349, 1969.

ROWLEY, J. E. Organizing Knowledge: an Introduction to Information Retrieval. 2. ed. England: Ashgate, 1992. 509 p.

Santos, R. N. Produção científica: por que medir? O que medir? Revista Digital de Biblioteconomia e Ciência da Informação, v. 1 , n. 1, p. 22-38, 2003.

SANTOS, E. M.; NETO, J. D. O.; ARAÚJO, E. M.; OLIVEIRA, S. R. M.; BARBOSA, D. H.; ZANDER, V. T. Educação à distância no Brasil: evolução da produção científica. EESC-USP, Departamento de Engenharia de Produção: 2007. 11 p. Relatório de Pesquisa.

SMIRAGLIA, R. P. The progress of theory in knowledge organization. Library Trends, v. 50, n. 3, p. 330-349, 2002.

SPINAK, E. Indicadores cienciométricos. Ciência da Informação, v. 27, n. 2, p.141-148, 1998.

TRISTÃO, A. M. D.; FACHIN, G. R. B.; ALARCON, O. E. Sistema de classificação facetada e tesauros: instrumentos para Organização do Conhecimento. Ciência da Informação, v. 33, n. 02, p.161-171, 2004. 


\section{Dados da autora}

Cláudia Daniele de Souza

Possui graduação em Biblioteconomia e Ciência da Informação $(\mathrm{BCl})$ e Mestrado na linha de pesquisa Gestão Tecnológica e Sociedade Sustentável do Programa de Pós Graduação em Ciência, Tecnologia e Sociedade (PPGCTS), do Departamento de Ciência da Informação (DCI) da Universidade Federal de São Carlos (UFSCar), com período de estágio na Universidade Carlos III de Madrid (UC3M), Espanha. Atua principalmente nas áreas de organização da informação, bases de dados, bibliometria, avaliação de produção científica e indicadores de ciência, tecnologia e inovação.

claudia zenaro@yahoo.com.br

Recebido-Received : 2013-05-22

Aceito - Accepted : :2013-06-30

(c) EY $_{\text {EY }}$ New articles in this journal are licensed under a Creative Commons Attribution 3.0 United States License.

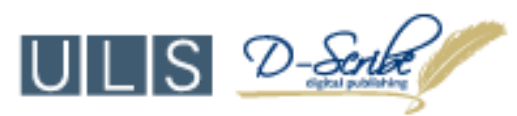

This journal is published by the University Library System of the University of Pittsburgh as part of its D-Scribe Digital Publishing Program and is cosponsored by the University of Pittsburgh Press. 